\title{
نهو مشروع ثقافي أصيل في فكر ابن حزم الأندلسي
}

\section{نعمان بوقزة}

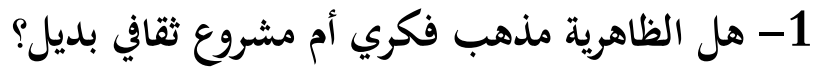

ليس من الموضوعية في شيء أن يجاب عن هذا السؤال الملح والمشروع في الوقت نفسه إلاّ بعد عملية تحليلية للنظرية الظاهرية من خلال تفكيك البنية الفكرية الممثلة في آراء ابن حزم القرطبي الفقهية والأصولية والعقدية واللغوية، وهذه الآراء المشكلة لمنظومة معرفية متماسكة تستحق إعادة نقد وقراءة على ضوء المعطيات الاجتماعية والثقافية والسياسية التي تمثل السياق التاريخي الذي ظهرت فيه الحركة الظاهرية في الأندلس وبلاد المغرب. ثم إن محاولة فهم الأصول التي بنيت عليها الحزمية تفيدنا في استكشاف حقيقة هذا الحركة من حيث بعدها السياسي وخطورتا على الاتحاه الفكري السائد في ذلك الوقت.

نودّ في هذا المقام التأكيد على ملاحظة مهمة تخص تراث ابن حزم الذي لا يزال غير معروف أو مدروس بالقدر الكافي ولعل السبب الرئيس لهذا القصور راجع إلى مواقف لا تمت بصلة للموضوعية المتوخاة في دراسة التراث بكل مدارسه وآرائه وآفاقه. وإننا في هذه العجالة نحاول التأكيد على ما أكد عليه سلفنا وذلك بتسليط الأضواء على أهم الجوانب المتعلقة بالظاهرية الحزمية كتيار فكري مشبع بالأصالة، ترك آثارأ لا يمكن نكراها في حضارة الأندلس وبلاد المغرب، وكمشروع واحد ييشر بالتجديد في مستويات معرفية، وإن كان مفتقراً لبعض الآيات والآداب المناسبة التي كثيراً ما يصادفنا عكسها ونحن نطرق أبواب الأفكار والمذاهب في بدايات تشكلها الأولى شرقاً وغرباً.

ونود أن نلمح للقارئ بأننا سنطلق من رؤية خاصة ترى في فكر ابن حزم وقراءته المتميزة للنص اعتماداً على سلطة اللغة ذاتما بديلاً فكرياً ومنهجياً يقف كلبنة أولى لمشروع ثقافي إسلامي منبته الأندلس ركس وفروعه في البلاد الإسلامية، وهذا المشروع طبعاً - من وجهة نظر معرفية - يستهدف إحياء أصول الثقافة الإسلامية وإعادة الاعتبار لسلطان النص والعقل اللذين شوهتهما مشاريع ثقافية أخرى كانت تتغذى من

\footnotetext{
* طالب دكتوراه بجامعة باجي مختار -عنابة- الجزائر، ماجستير في اللسانيات وأستاذ مساعد بكلية الآداب واللغات بالجامعة.
} 
الثقافة الغنوصية وبعض الاتحاهات التي لا تنفض يديها من الاعتماد على العرفان واكتناه الأسرار الربانية بل وتعطيل السنن الكونية والدعوة لعجز العقل من جهة وعدم الوثوق باللغة من جهة ثانية، وربما كانت هذه الآراء هي السبب في انتشار الفساد والثبرير له اجتماعياً وسياسياً وعقدياً. ولقد كان عالمنا في خصامه لبعض الفقهاء بغض النظر عن اتجاهاقم المذهبية يطمح لإعادة تأسيس الثقافة العربية الإسلامية على مبدأ أصيل

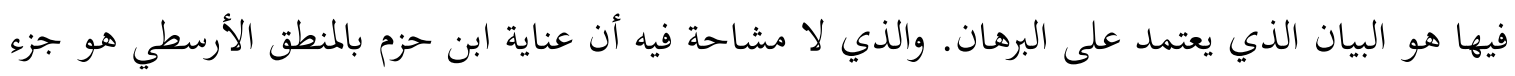
من عنايته بالبيان الذي يتأسس عليه نظرية وتطبيقاً منهج قراءة النصوص وتفسيرها واستباط الأحكام التكليفية منها. وبالمثل كان إلحاحه في غير موضع في كتبه على ضرورة الالتزام بما يفهم من ظاهر اللفظ وما

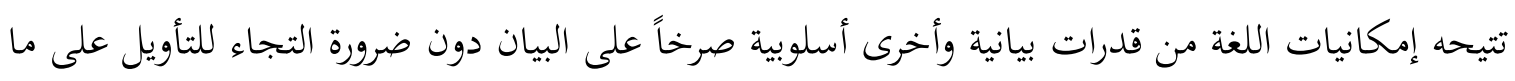
في هذه الرؤية من إقصاء حاد لأصل بنيت عليه أطروحات مناقضة للظاهرة اللغوية ومن العلوم أن رفض التأويل على غير مقتضى اللسان العربي في النص يفضي ضرورة إلى إنكار المجاز غير المسوّغ كظاهرة لغوية، مما يسهّل على الظاهرة مهمة الرّد على علماء الكلام في مسألة الصفات الإلهية خاصة، ورد كل أدلة الشيعة ورؤوس الأحزاب والفرق في الإمامة وتفاصيلها انطلاقاً من النص وحده.

كما أن السير وراء التأويل وفق هذه الرؤية يجعل قراءة النص خارجية، في حين يفترض من المجتهد أن ينطلق من النص نفسه وتركيبه ودلالات ألفاظه دون أن يتعب ذهنه في البحث عن الدلالات الخافية، وما يمكن أن يفهم بعد منطوق النص. والحقيقة أن منهج ابن حزم هذا المعتمد على البيان رأساً يتمشى مع طبيعة المعجزة القرآنية بوصفها دليلاً بيانياً أقامه صاحب المعجزة على العرب أهل البيان فتكون بذلك المعادلة متساوية الأبعاد ولو افترضنا طبيعة أخرى للنص المعجز لما كانت للمعجزة قيمة حين تخالف في جنسها وطبيعتها الهدف الذي أوجدت له.

إنه من الضرورة بمكان أن يقارن ابن حزم في ظاهريته هذه بالتيارات الفقهية والكلامية والفلسفية في زمانه ليتم الإدراك الواعي بتفوّقه وجدية أطروحاته دون حاجة إلى مزايدات مبنية على مواقف ذاتية وأهواء مذهبية، ولسنا في حاجة إلى أن يقنع بعضنا بعضاً بأغا روافد رغم اختلافها، وربما تناقضاها تصب في النهر 
الخالد غر الثقافة الاسلامية التي ندين لها بضرورة نقدها وغربلتها من جديد وتقديمها في ثوبها الأصيل بكل طاقاتها الخلاقة وأفكارها التجديدية للعالم في إطار أسلمة المعرفة.

وفي إطار هذا الموقف نؤكد على نقطة مهمة هي أن الدّعوة الظّاهرية إن سمح لنا اعتبارها كذلك ابتحاه فكري نقدي لم يكن هدفه النيل من رموز فقهية معينة بقدر ما كان دعوة إلى تغيير الفكر العربي وبحديد رؤيته لأمهات القضايا التي تمس الناس في حياقم ومعادهم، كما يجب أن يفهم من حدة طبع رائد هذا الاتحاه غيرته على أصول الدين وطموحه الناجح لهدف نبيل. ولا أكون مبالغاً إذا قلت: إن الآراء الصائبة التي سادت عبر الزمن لم يكن لها خيار في استعمال لغة كلغة ابن حزم في كثير من الأحيان، فإن لم يكن "الجدال بالتي هي أحسن" سلاحها، كان السلطان موصلها لعقول الناس قبل قلوبكم.

ويمكنا أيضاً أن ندرس نشأة هذا المذهب وتطوره وآثاره العلمية والسياسية ومنهجه الأصولي دون حاجة منا إلى إدراجه ضمن قائمة المذاهب الأثرية والنصية التي تقبلها أهل الأندلس ولم يتقبلوا غيرها لأسباب لا يسمح المقام بعرضها، واستبعادنا لمذه الحاجة مبني على تحول المنهج الظاهري من مجرد منهج أثري نصي إلى منهج لساني من طراز خاص تفكك به النصوص الدينية سواء أكانت إسلامية في الحوار الذي دار بين أساطين الفكر الفقهي كابن حزم والباجي مثلاً، أم اسلامية يهودية كنقد ابن حزم للكتاب المقدس في الفصل والرد على ابن التغريلة اليهودي، ورده كذلك وفق وجهة نظر ظاهرية على الفلاسفة والفرق الإسلامية. فلا غرو بعدئذٍ أن نعد حركته شمولية مبنية على منهج بياني برهاني واضح وضوح اللغة التي نزل ها الوحي، بل إن الظاهرية في التعامل مع النص وفق ما تتيحه إمكانات اللغة أضحت نزعة لدى الكثيرين، وقد كان المقريزي في مصر يكتب بهذه الروح، كما اضطلع الصوفي الشعراني بحفظ كثير من آراء الظاهرية، في حين يكثر الفخر الرازي من إيراد التفسير الظاهري للآيات، وبالروح نفسِها راح ابن مضاء القرطبي ثائراً على نظرية العامل في النحو العربي، وثورة ابن حزم على القياس والعلة وفروعها لا تفترق ثورتما كثيراً إلاّ في بعض الجزئيات التي يفرض اختلاف الموضوع حدوثها.

وسنحاول بعون الله مد الجسور للتعرف إلى بعض آراء ابن حزم المشكّلة لمنحى تفكيره العلمي والمنهجي دون أن ندّعي صحة ما ننسبه له فقد يكون انتصاراً له أو بتنياً عليه، وستكون أولى وقفاتنا مع 
نظريته في اكتساب المعرفة ثم نعرض لملامح منهجه العلمي التي تظهر عقلانيته المتزنة، وفي ضوئها نحدد موقفه من المنطق والفلسفة القياس، ثم نعرض لمفهوم الدليل وحجيته في النظرية الحزمية لنختم كلامنا بتحديد معالم الظاهرية الحزمية في ضوء مفهوم البيان القائم على البرهان.

\section{2- نظرية المعرفة عند ابن حزم ( الأصول والأبعاد)}

يُعَُّ ابن حزم الحسن مصدراً للمعرفة الإنسانية وسبيلاً موصلاً إلى النفس علماً أن العلاقة بينهما علاقة تأثر و تأثير، فإن عرض للنفس ما يشغلها عجزت الحواس عن أداء دورها المنوط بها. 1 ويلزم عند تعطيل دور الحواس تعرض صاحبها للخطأ في إصدار الأحكام، فقد يعتريه هيجان الصراء فيجد الحلو مراً، ومن في عينه ابتداء نزول الماء فيرى خيالات لا أصل لها. 2. ملما كانت الأحكام النابتحة نسبية كان لا بد من الاستنجاد بالعقل الذي أعطاه ابن حزم مكانة لائقة بقيمة الذي كان البارئ رسمه بها دون أن يطلق له العنان مثلما فعل غيره في أن يتعرف المجهول الغائب، وليس أدل على ذلك من استنجاده به حين يعوزه الدليل النصي في رد أقوال أهل الكتاب فكثيرة هي الردود التي اختفى بها الفصل والتي بنيت رأساً على توجيه العقل والمنطق.3 3 وقد غدا العقل ميزاناً يرفض به كل ما يعارض الحقائق الإسلامية في قصص الأنبياء ويطرحها على أها ترَّهات لا سند لها، ويشيد به في التقريب بقوله: ".... ومن كذب عقله فقد كذب شهادة الذي لولاه لم يعرف ربه وحصل في حال الجنون، ولم يحصل على حقيقة...".

غير أنه يضع له حدوداً يجب أن لا يتعداها، فليس من واجبات العقل إيجاب شيء أو منعه، كما أنه ليس من خصوصياته تحسين أمر أو تقبيحه مثلما ذهب إلى ذلك المعتزلة، بل دوره يكمن في أن يفهم من الله ويقر بأنه يفعل ما يشاء، ولو شاء الله أن يحرم ما أحل أو يحل ما حرم لكان له. 5

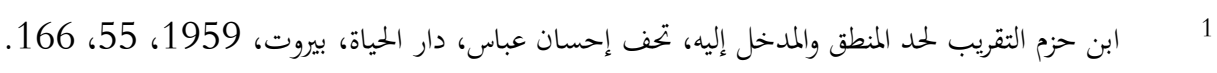

$$
\begin{aligned}
& 2 \text { 2 } 2 \\
& 3 \\
& 4 \\
& 5 \text { 5 الفصل، 199/5، والإحكام في أصول الأحكام، مطبعة الإمام، مصر، 28/10. }
\end{aligned}
$$


ويسلك ابن حزم مسلكاً مغيراً يكشف عن الدور التربوي الذي يقوم به العقل في توجيه وإرشاد الإنسان في معاشه ومعاده، فيه تستعمل الطاعات وبتتبب المعاصي، والعقل من نجى نفسه من عذاب النار،

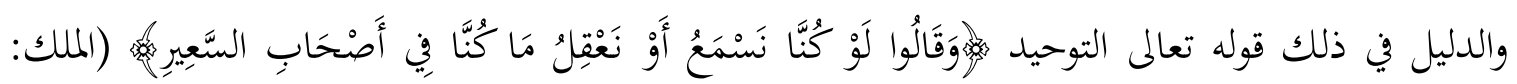
10)، ثم يرفع شعاراً للعقل يجعل منه خضوعاً للحق بعد إدراكه مع سياسة الدنيا لتكون مزرعة للآخرة.6 ومن العقل ما لا يختلف عليه شخصان معافان من كل بلاء ومصدر هذا الاتفاق فطرة الانسان. وعلم نفسه على حد تعبير ابن حزم كعلم النفس أن الجزء أقل من الكل وعدم اجتماع المتضادين وعدم ظهور جسم واحد في مكانين خختلفين. ${ }^{7}$ في حين يرجع ابن حزم خطأ استعمال هذه القوة الفطرية عند العلماء إلى سببين: أحدها يتمثل في طول وكثرة المقدمات إلى درجة يصعب فيها رد هذه المقدمات إلى البديهيات ككثرة الأعداد والأرقام في العمليات الحسابية، وثانيهما خروج العقل عن منهجه الموضوعي واستسلامه لنزوات النفي وإغراءات الهوى واتباع المتشابهات وعدم الخضوع للحقائق والميل إلى الرأي والتأوي 8 الباطل.

ويهتم ابن حزم بقيمة الخبر المتواتر في إيجاب العلم والبلدان والعلماء والملوك والوقائع والتواليف، ولا يجتاج في ضوء هذا الموقف إلى دليل يدعم ما جاء به الخبر، وإن ادعى مدع وجوب ذلك لزمه إثبات نسبه إلى أمه وأبيه وعشيرته، 9 وبعد أن يتبين اختلاف الناس في العدد الذي يتحقق به التواتر الخبري، وهذا اختلاف متهافت ليس له ما يبرره سوى ميول ذاتية لبعض الأحداث في حياة الأمة يجنح لضرورة الاحتياط لمنع التواطؤ على الكذب في الحبر المنقول، ولا يهم فيها العدد كثيراً فقد يكذب الكثير ويصدق الواحد. 10 والحق أن العلم الضروري لا يثبت إلا بالتواتر مع العدد، وفي ضوء ذلك نقرأ له،: "وقد يضطر الخبر الواحد إلى العلم بالصحة، إلاّ أن اضطراره ليس بمطرد ولا في كل وقت ولكن على قدر ما يتهيأ". 11

$$
\begin{aligned}
& 6 \text { ا } 7 \text { ابن حزم، الأخلاق والسير في مداواة النفوس، دار البعث، قسنطينة، 1982، ص58، } 59 . \\
& 7 \\
& 8 \\
& 9
\end{aligned}
$$

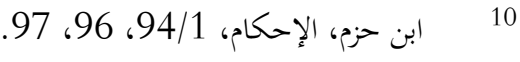

$$
\begin{aligned}
& 11 \text { 1 } 10
\end{aligned}
$$




\section{3-ملامح المنهج العقلي والتفكير العلمي عند ابن حزم}

في فكر ابن حزم بالإضافة إلى ما سبق ذكره تتأكد ملامح المنهج العقلي حين يدعو إلى احترام سنن الله في الكون وهي سنن لا يمكن خرقها إلا من الله عزّ وجل، فتغدو هذه السنن ثابتة مستقرة كأفها صفات ذاتية جبلت عليها المخلوقات في الكون الفسيح، ويظهر من قوله معلاًا: "لأن من الصفات الممولة في الوصف ما هو ذاتي به، لا يتوهّم زواله إلاّ بفساد حامله وسقوط الاسم عنه، كصفات الخمر التي إن زالت عنها صارت حلاً وبطل اسم الخمر عنها...". 12

وفي ضوء هذه السنن الكونية الظاهرة للإنسان عن طريق الحواس والعقل والتجربة والخبر لا يمكن التسليم بكثير من الخوارق التي نص عليها الكتاب المقدس في شأن اليهود، فهؤلاء السحرة الذين كلفهم فرعون بالتصدي لموسى عليه السلام استطاعوا تحويل ماء النهر إلى دم ونقل ضفادع الماء إلى أرض مصر لتملأها وترعب الناس، في الحقيقة لم يخرقوا نظم الكون بل موهوا على الناظرين واحتالوا عليهم، ووفق هذه الرؤيا التي لا تخلوا من نزوع إلى الظاهر يفسر ابن حزم كثيراً من نصوص التوراة التي حرّفها اليهود. 13 وتظل المعجزة باعتبارها قيمة إلهية مرتبطة بالنبوة والرسالة فقط. وتبقى كلمة لا بد من ذكرها وهي أن ابن حزم كان نقلياً في مواضع لا يجوز فيّها إلاّ ذاك وعقلياً في مقامات لا يمكن التفاهم فيها إلاّ بالركون إلى سلطان العقل، وقد أفصح هو ذاته عن هذا المبدأ في كتابه الأحكام، 14 ويمكن إجمال المواضع التي بدت فيها حواراته العقلية في مناقشته للسوفسطائية والفلاسفة والفرق الدينية والمذاهب الاسلامية في أصول عقائدها.

\section{4- - مواقف ابن حزم من المنطق والفلسفة}

$$
12
$$

الفصل، 155/1، وانظر سفر الخروج، الفصل 7، 8، انظر رأي عبد الفتاح الغاوي، النبوة بين الفلسفة والتصوف، رسالة دكتوراة

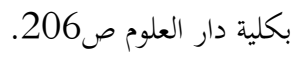

الإحكام، 17/1 وانظر تفرقة ابن حزم والواضحة بين السحر والمعجزة النبوية في المحلى 36/1، 37. "السحر حيل وتخيل ولا يحيل

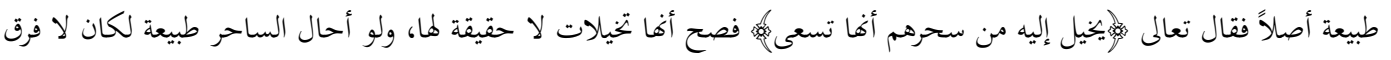

$$
\text { بينه وبين النبي، وهذا كفر من أجازه. }
$$


يؤمن ابن حزم بجدوى المنطق وقيمته في سلم المعارف الإنسانية واعتباره سبيلاً برهانياً لثبوت التوحيد ومعرفة الشريعة، ويظهر ذلك في مقدمة كتابه التقريب لحدود المنطق، إذ اعتبر المنطق وسيلة لفهم الأشياء التي نص الله تعالى ورسوله عليها وما تحتوي عليها من المعاني التي تقع عليها الأحكام وما يخرج عنها من المسميات وانتسابها تحت الأحكام على حسب ذلك، 15 بل لا يستجيز الفتيا لمن لم يطلع على المنطق، ذلك لك أنه جاهل بحدود الكلام وبناء بعضه على بعض وتقديم المقدمات وانتاجها النتائج التي يقوم بها البرهان، وإزاء هذا الموقف لا يغض الطرف عن العلاقة الحميمة بين المنطق والشريعة يقف ابن حزم صلباً معانداً لكل الهجمات التي حاولت النيل منه والتشهير به لاشتغاله بعلوم الأوائل.

ولعله من الغريب أن يمتدح الفلسفة ويدافع عنها في بيئة اشتهرت بهجوم الفقهاء على الفلسفة عامةً ودعاة المنطق خاصةً في إطار حملة منظمة، تحذر وتتهم كل متمنطق بتهمة التزندق كمرحلة أولى للإطاحة به، بل تزداد الغرابة خين يعتبر الفلسفة معناها وثمرتا طريقاً لإصلاح النفس وحسن سيرتا المؤدية إلى سلامتها في معادها وحسن سياساتا في حياتا. 16

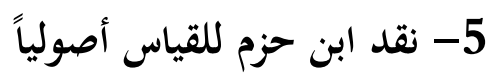

يرد ابن حزم في إطار وجهة نظر منهجية القياس في التفكير الأصولي، ذلك أن مدارس فقهية يمكن إدراجها تحت مدرسة كبرى تتأسس على الرأي في تطبيقاةا لآليات القياس كانت تؤلف بين عناصر مختلفة في طبائعها لا يمكن اعتبارها متوافقة رغم تشاهها، وهذا التشابه لا يمكن أن يتخذ مطية لسحب الأحكام الثابتة على ما لم يثبت في حكم نصاً، كما أن الظنية لا تنتفي عن التشريع الذي يستمد مرجعيته من الكتاب، وهذا الأخير قطعي لا بجال للتأويل فيه، ويمكنا اراء هذه الرؤيا الحزمية أن نعُعَّ هذا الموقف أساساً لنظرية خاصة في تاريخ الاجتهاد الاسلامي تستمد قوتا من المنهج الظاهري الذي يعتمد تفسير النصوص من ذاتما بعيداً عن مفاهيم الباطن والمعرفة البعدية والدلالات الخاصة، وما إلى ذلك من الآليات التي يقترحها منهج التفسير بالرأي.

16 15


وفي إطار رفضه للقياس يرفض كذلك الاستدلال بالشاهد عن الغائب لخروجه عن بديهة العقل التي تقتضي بالتفرقة بين عالم الغيب والشهادة، كما ينكر على القائلين بقياس التمثيل أخذهم به، ذلك بأن هذا النوع لا يقوم على أسس مضبوطة، مما ينجم عنه الخطأ في الحكم رغم سعي الأصوليين إلى جعل العلة الجامعة بين الأصل والفرع وصفاً منضبطاً مطرداً غير مضطرب على جهة القطع. 17

ولعلنا لا نكون مبالغين إذا قلنا إن ابن حزم في حركته الثورية تلك ضد القياس كان يستشعر ظهور ادّعاء أنصار القياس تصريحاً أو تضميناً غياب النص في نوازل لم يرد لها حكم في كلام الله أو سنة نبيه صلى الله عليه وسلم، مما سيفسح المجال لكثير من الأطراف في غياب المرجعية النصية لكي تحتال على الشريعة وتفرض آراءها تحليلاً وتحيماً توطؤً في أحيان كثيرة مع رغبات ذاتية يجسدها فساد أخلاقي واجتماعي عاينه الرجل في البيئة الأندلسية المتميزة بخصوصيات اجتماعية وثقافية وسياسية.

ومن جهة ثانية لعله كان يرى في القياس الفقهي وأشكاله نوعاً من السفطة والتحكم الضعيف، ذلك أن البحث عن العلة في الفرع والأصل تتم عند القياسيين باستقراء لا يمكن أن يكون تاماً برهانياً لذلك نجده ينكر على من لا يوجب اختلاف الحمم في حال افتراق السبه، مثلما يوجب استواءه في اجتماعه في قياس الشبه. 18 أما قياس العلة فغير معمول به أصلاً في الشريعة، وإن كان مستساغاً في الطبيعيات، 19 إلاّ أنه يجوز العمل به في الشريعة إذا نص النص نفسه على وجود العلة في الحكم.

ويحلو لنا ونحن نبسط رؤيته هذه على مائدة الحوار إن نعدها شكلاً من أشكال التوسيع والترخيص للناس في حياقم الدينية. إذ ليس للعقل وكل آلياته سلطان في التحريع أو التحليل، فيضحي كل شيء لم ينص فيه بحكم مباحاً سهلاً للأخذ. وعلى ما في هذه الفكرة من وجاهة نقف متعجبين ممن ناصب ابن حزم العداء واتمه بالتعصب من حيث كان هذا الأخير ساعياً للتيسير على الناس، ولعل ابن حزم كان محقاً حين قال: "... وأما جهتنا فالحكم في ذلك ما جرى به المثل السائر أزهد الناس في عالمِ أهلُه ... وقرأت في الإنجيل أن عيسى عليه السلام قال: لا يفقد النبي حرمته إلاّ في بلده".

$$
\begin{aligned}
& 17 \\
& 18 \\
& \text { المصدر نفسه، ص169. }
\end{aligned}
$$




\section{6- - - مفهوم الدليل وحجيته في النظرية}

لا بد ونحن نصف عناصر البنية الفكرية التي تؤطر فكر ابن حزم أن نتطرق ولو بشكل مجمل لمفهوم

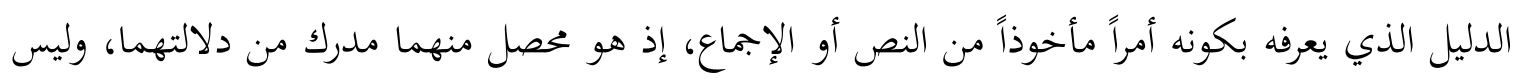
الدليل باعتباره مصدر استنباط حملاً على النص أو الإجماع عنده عن طريق النظر في العلل، بل هو أمر مأخوذ من النص نفسِه، ولهذا تنتفي التسوية بين الدليل المؤسس على النص عند ابن حزم ومفهوم القياس عند القائمين به.

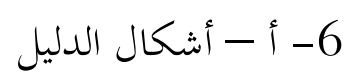

$$
\text { يبين ابن حزم انقسام الدليل إلى أقسام أهمها: - n }
$$

6 - أ - 1 - اشتمال النص على مقدمتين دون التنصص على النتيجة التي يكون استخراجها دليلاً، والأكيد في هذا الأنموذج أن الحاصل ليس قياساً لفرع على أصل لعلة جامعة بينهما سواء نص النص على العلة أم لم ينص عليها.

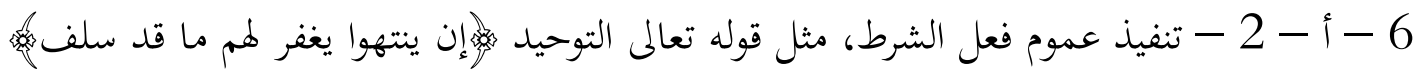
والشرط هنا يقتضي أن كل من يغفر له الله شركاً كان أم غيره.

6 - أ - 3 - تضمن المعنى الذي يحمله اللفظ في ذاته نفي معنى آخر لا يجوز اجتماعه مع معنى اللفظ المقصود كتضمن لفظة أف في قوله تعالى والضرب واستحالة اجتماع هذين المعنيين مع معنى الإحسان لمما والتقرب إليهما.

6 - أ - 4 - أما الشكل الرابع فيتمثل في عدم التنصيص على حكم الشيء الذي إما أن يكون حراماً بالنص وحكم الإثم في الفعل، وإما أن يكون فرضاً بالنص فيأثم التارك له، وإما أن يكون مباحاً إذا لم 
ينص على أحد الحكمين السابقين، والحقيقة أن هذا النوع أدخل في باب الاستصحاب عند الظاهرية وسنعرض له في محلّه.

وربما يتبادر إلى الأذهان سؤال عن جدوى استقلالية الدليل كمصدر رابع في التفكير الظاهري رغم كونه نتاج النظر في النص ذاته، والجواب أن ابن حزم ينكر التأويل البعيد ويحرص على الدلالة الظاهرة للنص، لما كانت هذه الصور ممثلة بما تضمنته ودلالات الألفاظ من معان تأخذ بالتأمل، وليست أخذاً بظاهر اللفظ وإن كانت متفرعة ومشتقة عنه وهو السبب المباشر لإخراجها مستقلة عن سائر الأدلة. 21 والحقيقة أن ما ذكر آنفاً من أقسام إضافة إلى أنواع أخرى هي أقرب ما تكون للبراهين المنطقية التي تعكس صدى المنطق في دراسات ابن حزم للشريعة من جهة، وترتبط بالنص القرآني والحديث النبوي من جهة ثانية، في حين يقدم الإجماع عند الظاهرية أشكالاً أخرى للدليل أهمها استصحاب الحال. وأقل ما قيل وإجماعهم على ترك قولة ما وإجماعهم على أن حكم المسلمين سواء.

وخلاصة هذه الأدلة مبسوطة في كتاب الأحكام كما تناولها غير أصولي موافقاً لأصول الظاهرية أو مخالفاً لمم، غير أن ما يهم في هذه الأدلة كلها موقف ابن حزم من الاستصحاب الذي يعرفه بأنه بقاء حكم الأصل الثابت بالنصوص حتى يقوم الدليل عنها على التغيير،22 فيكون هذا المصدر بدوره مؤسساً على بنى النص وليس على يجرد أصل ثابت من الإباحة الأصلية. 23 ويبدو أن أغلب المتكلمين ينكرون حجيته في الشرعيات دون الحسيات التي أجرى الله فيها العادة بالاستصحاب، في حين يثبته الظاهرية والشافعية

24 والمالكية.

$$
\begin{aligned}
& \text { 20 } \\
& 21 \\
& 22 \text { 2 } \\
& 23 \text { و وهبة الزحبلي، أصول الفقه الإسلامي، دار الفكر المعاصر، دار الفكر، لبنان، دمشق، }
\end{aligned}
$$

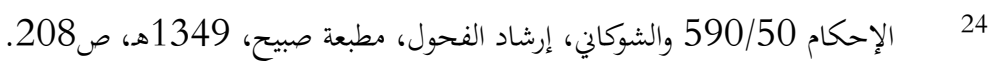


إن استصحاب الحال عند ابن حزم تعبير عن عدم مراوحة الحكم الشرعي لنص المستدل به عليه فهو

يدور معه وجوداً أو عدماً، فإن وجد النص وجد الحكم بالحل أو الحرمة، وإن لم يوجد فهو على الإباحة نزولاً

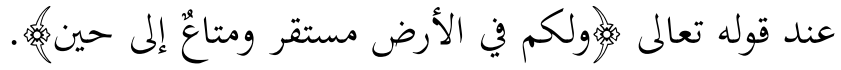

\section{7- ظاهرية ابن حزم في ضوء مفهوم البيان}

يصر ابن حزم على وجوب وضوح المعنى في الكلمة والجملة على حد سواء، غير أن المعنى الظاهر للكلمة كما يعدّه ابن حزم وما يجب أن نفهمه نخن ليس المعنى الذي تستقبله الأذن المشتتة غير المنتبهة والتي تجعله بعيداً عن الدقة قريباً من الغموض، إنما المعنى المقصود هو المرتبط بالفهم العميق لمبدأ اللغة، لذلك بك بكريك انشغل ابن حزم في مشروعه البياني بالوضوح اللغوي في إطار التعريفات. والمعرفة كلها فقهاً أم أصولاً أم فلسفة مبنية على التعريف. 25 ويمكنا بعد الاطلاع على عمل ابن حزم في هذا الموضوع من الموضوع المذكور سلفاً تبيان رؤيته البيانية القائمة على تحليل الألفاظ وتمييز معانيها منعاً لأي خلط أو التباس أو إبهام، ثم إن مهمة المفسر للنصوص أن يقتصر على استخلاص معاني الكلمات والعلاقات بينها بغية تتبعها بوصفها قواعد يمكن ممارستها على نحو عملي مترابط، وتتبدى الرؤية الحزمية الحرفية بإلغاء الثنائية القائمة بين المعاني العامة والخاصة فيبطل بذلك التمييز بين المراد والظاهر كنتيجة لإنشاء المعادلة بين العام والخاص، فاللغة أولاً وأخيراً ليست لغزاً من الألغاز المبهمة كما أن هذا الموقف هو أصلح دعوة إلى نظرية يمكن أن نسميها بنظرية العموم.26 والمتفحص لأعماله من جهة ثانية يكتشف مدى عمومية هذه الرؤية وتحوها إلى منهج قراءة في معارف متعددة فهذه الظاهرية البيانية تلوح في عمله الفقهي والأصولي، كما تبرز في وضوح في حواره مع اليهود والنصارى في الرد على ابن النغريلة وكتاب الفصل، كما تتأكد نظرياً في الأحكام وكتابه التقريب ناهيك عن رسالة إبطال القياس والاستحسان.

لقد استطاع ابن حزم أن يقيم مذهبه البياني في جميع المسائل الكلامية وأن يطبق أصول منهجه القائم على البعد اللساني تطبيقاً بارعاً في حجة مبسوطة لم تعرض بكيفية دقيقة -فيما نعلم- إلاّ عنده، ولقد لخص

$$
\text { 25 }
$$

Armaldez Grammaire et theologie chez Ibn Hazem decordoue. Essai sur la structure 26 et les conditions de la pense musulmane, Paris 1956, P130-133. 
منهجه البياني هذا بقوله: "إن كلام الله تعالى واجب أن يحمل على ظاهره، ولا يحال عن ظاهره البتة إلاّ أن

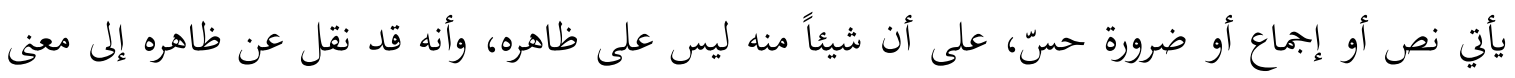
آخر، فالانقياد واجب علينا لما أوجبه ذلك النص أو الاجماع أو الضرورة، لأن كلام الله تعالى أو أخباره

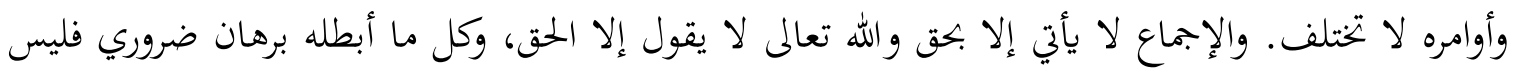

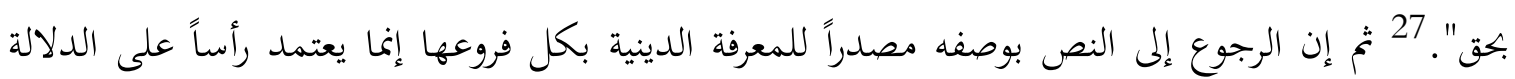
اللغوية ومبدأ المواضعة خاصة، ولا يمكن لأحد تحت غطاء التأويل وباسم المجاز أن يحيل الألفاظ عن دلالاتحا

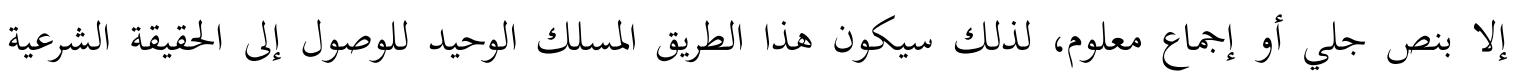
المشفوعة بالبرهان العقلي والمزود بحجية ضرورات الحسن. 28 ثم إن الرجوع إلى ظاهر النص ليس بالأمر الهين كما ييدو لبعضهم؛ فليس الظاهر بجرد قشرة خارجية

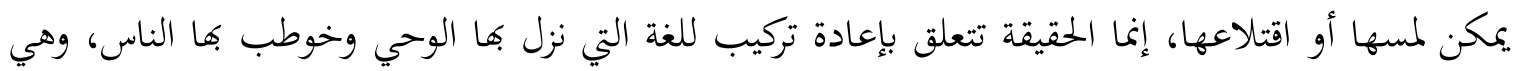
في نظر ابن حزم المسؤول الوحيد عن تفسير الفكر الإسلامي الذي يستمد سلطانه من الوحي الإلمي، وهذا الأخير يمد قوته في البرهان من خلال بلاغتها ووضوحها وبيان دلالاقا.

أخيراً يكننا وبدون مبالغة القول إن ابن حزم قد أدرك طبيعة المأزق الذي وقعت فيه الأمة في زمنه وقد كان مأزقاً خطيراً يهدد الحضارة الإسلامية في عمق وجودها، وكان من الازم القيام بثورة فكرية بجديدية مَبْدَوَها نقد الأصول بتأصيلها وطرح ما نتج من خيارات خاطئة ما زالت حضارتنا أسيرة لها إلى اليوم.

28 28 $\quad 27$

